- Regular Articles-

\title{
Studies on Cerebral Protection of Digoxin against Ischemia/Reperfusion Injury in Mice
}

\author{
Shaminder KAUR, ${ }^{a}$ Ashish K. ReHNI, ${ }^{b}$ Nirmal SINGH, ${ }^{*, a}$ and Amteshwar S. JAGGI ${ }^{a}$ \\ ${ }^{a}$ Department of Pharmaceutical Sciences and Drug Research, Punjabi University, Patiala-147002, \\ India, and ${ }^{b}$ Chitkara College of Pharmacy, Chandigarh-Patiala National Highway, \\ Rajpura-140401, Patiala, Punjab, India
}

(Received July 31, 2008; Accepted January 7, 2009)

\begin{abstract}
The present study was designed to investigate the possible neuroprotective effect of digoxin induced pharmacological preconditioning (PP) and its probable mechanism. Bilateral carotid artery occlusion (BCAO) of $17 \mathrm{~min}$ followed by reperfusion for $24 \mathrm{~h}$ was employed to produce ischemia and reperfusion $(\mathrm{I} / \mathrm{R})$ induced cerebral injury in male swiss albino mice. Cerebral infarct size was measured using triphenyltetrazolium chloride staining. Memory was assessed using elevated plus maze test. Degree of motor incoordination was evaluated using inclined beam walking test, rota rod test and lateral push test. Digoxin $(0.08 \mathrm{mg} / \mathrm{kg}$, i.p. $)$ was administered $24 \mathrm{~h}$ before surgery in a separate group of animals to induce PP. BCAO followed by reperfusion, produced significant rise in cerebral infarct size along with impairment of memory and motor coordination. Digoxin treatment produced a significant decrease in cerebral infarct size and reversal of $\mathrm{I} / \mathrm{R}$ induced impairment of memory and motor incoordination. Digoxin induced neuroprotective effect was abolished significantly by verapamil $(15 \mathrm{mg} / \mathrm{kg}$, i.p.), a L-type calcium channel blocker, ruthenium red $(3 \mathrm{mg} / \mathrm{kg}$, s.c. $)$, an intracellular ryanodine receptor blocker and 3,4-dichlorobenzamil $\left(\mathrm{Na}^{+} / \mathrm{Ca}^{2+}\right.$ exchanger inhibitor). These findings indicate that digoxin preconditioning exerts a marked neuroprotective effect on the ischemic brain, which is possibly linked to digitalis induced increase in intracellular calcium levels eventually leading to the activation of calcium sensitive signal transduction cascades.
\end{abstract}

Key words_- digoxin; pharmacological preconditioning; cerebral ischemia; verapamil; ruthenium red; $\mathrm{Na}^{+} / \mathrm{Ca}^{2+}$ exchanger; 3,4-dichlorobenzamil

\section{INTRODUCTION}

Ischemic stroke is a syndrome characterized by rapid onset of neurological injury due to interruption of blood flow to the brain. Because of the limited available therapeutic modalities, ischemic stroke still remains the leading cause of death. Researchers have directed their focus from time to time so as to develop some processes in order to contain or salvage the ischemic injury. Ischemic preconditioning (IPC) is a potent protective strategy introduced by Murray et al. ${ }^{1)}$ for the ischemic myocardium, which was later applied by Kitagawa et al., ${ }^{2)}$ to the ischemic neuronal injury as well. IPC has been demonstrated in other organ systems including kidney, ${ }^{3)}$ small intestine ${ }^{4)}$ skeletal muscle, ${ }^{5)}$ liver6) and spinal cord.7) Subsequently, many forms of preconditioning have been investigated, such as ischemic, pharmacological, thermal, or gas inhalation (particularly in lung injury).$^{8)}$ Furthermore, other neuroprotective phenomena like

*e-mail: nirmal_puru@ rediffmail.com, ashishkrehni@gmail.com remote ischemic preconditioning and ischemic postconditioning have also been put forth. ${ }^{9-12)}$

Following the discovery of the various molecular mechanisms involved in preconditioning, pharmacological agents are gradually replacing ischemia or hyperthermia, as the specific "targeted" pretreatment methods to protect organs from various types of injuries. Moreover, detailed mechanistic studies of these phenomena have indicated the possibility of precise pharmacological activation of certain biochemical transduction systems leading to the appearance of a preconditioning like protective effect that lasts beyond the agent's elimination, a phenomenon commonly referred to as pharmacological preconditioning (PP) . ${ }^{13)}$ Main advantage of the PP over IPC like interventions is its added clinical feasibility. ${ }^{14)}$ Some of the pharmacological agents that have been reported to elicit PP include the activators of cell membrane receptors like adenosine, $\alpha$-adrenergic, bradykinin, calcitonin gene related peptide (CGRP), and opioid receptors. ${ }^{15,16)}$ Studies have also documented that calcium ions play a fundamental role in multiple aspects of various forms of protective phenomenon like IPC 
and PP. ${ }^{17,18)}$ Recently cardiac glycoside ouabain, a potent inhibitor of $\mathrm{Na}^{+} \mathrm{K}^{+}$ATPase, has been found to exert a remarkable PP like protection of the ischemic myocardium. ${ }^{19)}$ Digoxin, another wellknown cardiac glycoside, is also known to inhibit $\mathrm{Na}^{+} \mathrm{K}^{+}$ATPase and subsequently leads to increase in intracellular calcium levels. ${ }^{20,21)}$ However potential of digoxin to induce PP like effects remain to be explored. Therefore, the present study was designed to investigate the possible neuroprotective effect of digoxin induced pharmacological preconditioning and its probable mechanism in mice.

\section{MATERIALS AND METHODS}

Male albino swiss mice weighing $25 \pm 2 \mathrm{~g}$, maintained on standard laboratory diet (Kisan Feeds Ltd., Mumbai, India) and having free access to tap water were employed in the present study. They were housed in the departmental animal house and were exposed to $12 \mathrm{~h}$ cycle of light and dark. The experiments were conducted in a semi-sound proof laboratory. The experimental protocol was approved by institutional animal ethics committee (IAEC) and care of the animals was carried out as per the guidelines of committee for the purpose of control and supervision of experiments on animals (CPCSEA), Ministry of Environment and Forest, Government of India (Reg. No.-107/1999/CPCSEA).

Drugs and Chemicals Digoxin $(0.08 \mathrm{mg} / \mathrm{kg}$, i.p.; Glaxo-Smithkline, Mumbai, India), verapamil $(15 \mathrm{mg} / \mathrm{kg}$, i.p.; Torrent Pharmaceuticals, Ahmedabad, India), ruthenium red $(3 \mathrm{mg} / \mathrm{kg}$, s.c.; Loba Chemie, Mumbai, India) and chloral hydrate (Riedel-deHaen, Germany) were dissolved in normal saline. 3,4-dichlorobenzamil $(0.5 \mathrm{mg} / \mathrm{kg}$, i.p.; SigmaAldrich Ltd., St. Louis, Mo, USA) was dissolved in $0.5 \mathrm{M}$ dimethylsulfoxide (DMSO) solution. All other chemicals used in the present study were of analytical quality. All drug solutions were freshly prepared before use.

Ischemia-reperfusion Induced Cerebral Injury

Mice were anaesthetized using chloral hydrate (400 $\mathrm{mg} / \mathrm{kg}$, i.p.). A midline ventral incision was made in the neck to expose right and left common carotid arteries, which were isolated from surrounding tissue and vagus nerve. A cotton thread was passed below each of the carotid artery. Global cerebral ischemia was induced by occluding the carotid arteries. After $17 \mathrm{~min}$ of global cerebral ischemia, the incision was sutured back in layers and reperfusion was allowed for $24 \mathrm{~h} .{ }^{23)}$ The sutured area was cleaned with $70 \%$ ethanol and was sprayed with antiseptic dusting powder. The animals were shifted individually to their home cage and were allowed to recover.

A single dose of digoxin $(0.08 \mathrm{mg} / \mathrm{kg}$, i.p. $)$ was given $24 \mathrm{~h}$ prior to the global cerebral ischemia so as to induce pharmacological (drug induced) preconditioning.

Assessment of Cerebral Infarct Size At the end of $24 \mathrm{~h}$ of reperfusion after global cerebral ischemia, animals were sacrificed by spinal dislocation and the brain was removed and placed immediately in ice cold saline for $10 \mathrm{~min}$. Brain sample was then sliced into uniform coronal sections of about $1 \mathrm{~mm}$ thickness. The slices were incubated in 1\% triphenyltetrazolium chloride (TTC) at $37^{\circ} \mathrm{C}$ in $0.2 \mathrm{M}$ tris buffer ( $\mathrm{pH} 7.4$ ) for $20 \mathrm{~min} .{ }^{24)}$ TTC is converted to red formazone pigment by NAD and lactate dehydrogenase and thus stained the viable cells deep red. The infarcted cells have lost the enzyme and cofactor and thus remained unstained dull yellow. The brain slices were placed over glass plate. A transparent plastic grid with 100 squares in $1 \mathrm{~cm}^{2}$ was placed over it. Average area of each brain slice was calculated by counting the number of squares on either side. Similarly, number of squares falling over non-stained dull yellow area was also counted. Infarcted area was expressed as a percentage of total brain volume. Whole brain slices were weighed. Infarcted dull yellow part was dissected out and weighed. Infarct size was expressed as percentage of total wet weight of brain.

\section{Assessment of Memory Using Elevated Plus Maze}

Test Plus maze consisted of two open $(16 \times 5 \mathrm{~cm})$ and two closed $(16 \times 5 \times 12 \mathrm{~cm})$ arms, connected by a central platform $(5 \times 5 \mathrm{~cm})$. The apparatus was elevated to a height of $25 \mathrm{~cm}$ above the floor. A fine line was drawn in the middle of the floor of each closed arm. All the animals were given a single trial per day on plus maze. Each mouse was individually placed at the end of an open arm facing away from central platform of the maze. The time taken by the mouse to enter from open arm with all the four legs into the closed arm was taken as transfer latency time (TLT). In case the animal did not enter the closed arm within $90 \mathrm{~s}$, it was gently pushed into the enclosed arm and TLT of $90 \mathrm{~s}$ was assigned to it. The animal was allowed to explore the maze for an additional $10 \mathrm{~s}$ after the measurement of TLT. ${ }^{25,26)}$ The 
animal was exposed to elevated plus maze for three consecutive days. ${ }^{27)}$ TLT recorded on the third day served as an index of acquisition. After recording day 3 TLT, the animal was subjected to global cerebral ischemia for 17 min followed by reperfusion for $24 \mathrm{~h}$. It was then again exposed to elevated plus maze on day 4. TLT measured on day 4 served as an index of memory. Utmost care was taken not to change the relative location of plus maze with respect to any object serving as visual clue in laboratory.

\section{Assessment of Motor Coordination}

Rota-rod test Rota rod has been used to evaluate motor coordination by testing the ability of mice to remain on revolving rod. ${ }^{28)}$ The apparatus consisted of horizontal rough metal rod of $3 \mathrm{~cm}$ diameter attached to a motor with variable speed. This $70 \mathrm{~cm}$ long rod was divided into four sections by wooden partitions. The rod was placed at a height of $50 \mathrm{~cm}$ to discourage the animals to jump from the rotating rod. The rate of rotation was adjusted to allow the normal mice to stay on it for five minutes. Each mouse was given five trials before the actual reading was taken. The animals staying on revolving rod for period of five minutes before the surgical procedure were selected and the test was again performed after $17 \mathrm{~min}$ of global cerebral ischemia and $24 \mathrm{~h}$ of reperfusion.

Inclined beam-walking test Inclined beam-walking test was employed to evaluate fore and hind limb motor coordination. ${ }^{29)}$ Each animal was individually placed on a metallic bar $55 \mathrm{~cm}$ long and $1.5 \mathrm{~cm}$ wide, inclined at an angle of $60^{\circ}$ from ground. The motor performance of mouse was graded on a scale ranging from 0 to 4 . A grade of 0 was assigned to animal that could readily traverse the beam, grade 1 was given to animal demonstrating mild impairment, grade 2 was assigned to animal demonstrating moderate impairment, grade 3 was given to animal demonstrating severe impairment and grade 4 was assigned to animal completely unable to walk on the beam. Inclined beam-walking test was performed before and $12 \mathrm{~h}, 24$ $\mathrm{h}$ after global cerebral ischemia and reperfusion.

Lateral push test Motor coordination was also evaluated by observing the percentage of mice showing resistance to lateral push. ${ }^{30)}$ Mouse was placed on a rough surface for firm grip and evaluated for resistance to lateral push from either side of shoulder. The test was performed before global cerebral ischaemia and $12 \mathrm{~h}, 24 \mathrm{~h}$ after global cerebral ischemia and reperfusion.
Experimental Protocol In total nine groups were employed and each group comprised of 10 animals.

Group I (Sham group): Mouse was subjected to surgical procedure and a thread was passed below the carotid arteries but they were not occluded. After 17 min, threads were removed and the animal was sutured back and allowed to recover for $24 \mathrm{~h}$.

Group II (Control group): Each mouse was subjected to $17 \mathrm{~min}$ global cerebral ischemia followed by reperfusion for $24 \mathrm{~h}$.

Group III (Digoxin sham group) : Digoxin $(0.08 \mathrm{mg} /$ $\mathrm{kg}$, i.p.) was administered $24 \mathrm{~h}$ before surgery. The rest of the procedure was the same as described for group-I.

Group IV (Verapamil sham group): Verapamil (15 $\mathrm{mg} / \mathrm{kg}$, i.p.) was administered $1 \mathrm{~h}$ before and $6 \mathrm{~h}, 12$ $\mathrm{h}, 18 \mathrm{~h}$ and $24 \mathrm{~h}$ following digoxin administration $(0.08 \mathrm{mg} / \mathrm{kg}$, i.p. $)$ which was administered $24 \mathrm{~h}$ before surgery. The rest of the procedure was the same as described for group-I.

Group V (Ruthenium red sham group) : Ruthenium red $(3 \mathrm{mg} / \mathrm{kg}$, s.c.) was administered $1 \mathrm{~h}$ before and 6 $\mathrm{h}, 12 \mathrm{~h}, 18 \mathrm{~h}$ and $24 \mathrm{~h}$ following digoxin administration $(0.08 \mathrm{mg} / \mathrm{kg}$, i.p. $)$ which was administered $24 \mathrm{~h}$ before surgery. The rest of the procedure was the same as described for group-I.

Group VI (Digoxin preconditioning group) : Digoxin $(0.08 \mathrm{mg} / \mathrm{kg}$, i.p. $)$ was administered $24 \mathrm{~h}$ prior to 17 min of global cerebral ischemia followed by reperfusion for $24 \mathrm{~h}$

Group VII (Verapamil control group): Verapamil $(15 \mathrm{mg} / \mathrm{kg}$, i.p. ) a voltage dependent L-type calcium channel blocker, was administered $1 \mathrm{~h}, 6 \mathrm{~h}, 12 \mathrm{~h}, 18 \mathrm{~h}$ and $24 \mathrm{~h}$ prior to $17 \mathrm{~min}$ global cerebral ischemia followed by reperfusion for $24 \mathrm{~h}$.

Group VIII (Verapamil+Digoxin preconditioning group): Verapamil ( $15 \mathrm{mg} / \mathrm{kg}$, i.p.) was administered $1 \mathrm{~h}$ before and $6 \mathrm{~h}, 12 \mathrm{~h}, 18 \mathrm{~h}$ and $24 \mathrm{~h}$ following digoxin administration. The rest of the procedure was the same as described for group-VI.

Group IX (Ruthenium red control group): Ruthenium red $(3 \mathrm{mg} / \mathrm{kg}$, s.c.) a ryanodine receptor blocker, was administered $1 \mathrm{~h}, 6 \mathrm{~h}, 12 \mathrm{~h}, 18 \mathrm{~h}$ and $24 \mathrm{~h}$ prior to 17 min global cerebral ischemia followed by reperfusion for $24 \mathrm{~h}$.

Group X (Ruthenium red + Digoxin preconditioning group): Ruthenium red ( $3 \mathrm{mg} / \mathrm{kg}$, s.c.) was administered $1 \mathrm{~h}$ before and $6 \mathrm{~h}, 12 \mathrm{~h}, 18 \mathrm{~h}$ and $24 \mathrm{~h}$ fol- 
lowing digoxin administration. The rest of the procedure was the same as described for group-VI.

Group XI (3,4-dichlorobenzamil control group) : 3,4dichlorobenzamil $(0.5 \mathrm{mg} / \mathrm{kg}$, i.p. $)$ a $\mathrm{Na}^{+} / \mathrm{Ca}^{2+}$ exchanger inhibitor, was administered $1 \mathrm{~h}, 6 \mathrm{~h}, 12 \mathrm{~h}, 18$ $\mathrm{h}$ and $24 \mathrm{~h}$ prior to $17 \mathrm{~min}$ global cerebral ischemia followed by reperfusion for $24 \mathrm{~h}$.

Group XII (3,4-dichlorobenzamil + Digoxin preconditioning group): 3,4-dichlorobenzamil $(0.5 \mathrm{mg} / \mathrm{kg}$, i.p.) was administered $1 \mathrm{~h}$ before and $6 \mathrm{~h}, 12 \mathrm{~h}, 18 \mathrm{~h}$ and $24 \mathrm{~h}$ following digoxin administration. The rest of the procedure was the same as described for groupVI.

Statistical Analysis The results were expressed as mean \pm standard error of means (S.E.M.). Statistical analysis for the results of infarct size, TLT and rota rod test was done using one-way ANOVA followed by Tukey's multiple range test as post-hoc analysis. Statistical significance for lateral push and inclined beam walking were calculated using Chi square and Wilcoxon rank sum test respectively. Statistical analysis for all the results was done using one-way ANOVA followed by Tukey's multiple range tests as post-hoc analysis. A value of $p<0.05$ was considered to be statistically significant.

\section{RESULTS}

Effect on Cerebral Infarct Size Global cerebral ischemia of $17 \mathrm{~min}$ followed by reperfusion for $24 \mathrm{~h}$ $(\mathrm{I} / \mathrm{R})$ produced significant increase $(p<0.001)$ in cerebral infarct size measured by both volume and weight method, when compared to the sham groups. Pharmacological preconditioning (PP) with digoxin, administered $24 \mathrm{~h}$ prior to I/R significantly attenuated $(p<0.01) \mathrm{I} / \mathrm{R}$ induced rise in cerebral infarct size. However, pretreatment of verapamil, ruthenium red as well as 3,4-dichlorobenzamil control did not affect $\mathrm{I} / \mathrm{R}$ induced rise in cerebral infarct size but significantly attenuated $(p<0.01)$ digoxin preconditioning induced decrease in infarct size (Fig. 1).

Effect on Memory Sham groups' animals showed a significant decrease $(p<0.05)$ in day 4 transfer latency time (TLT), when compared to their day 3 TLT, indicating normal retrieval of memory. On the other hand, control group animals undergoing global cerebral ischemia of 17 min followed by reperfusion for $24 \mathrm{~h}$ produced a significant increase $(p<$ 0.05 ) in day 4 TLT, when compared to day 4 TLT of sham groups' animals, indicating impairment of memory. PP with digoxin, administered $24 \mathrm{~h}$ prior to I/ $\mathrm{R}$, significantly $(p<0.05)$ attenuated $\mathrm{I} / \mathrm{R}$ induced in-

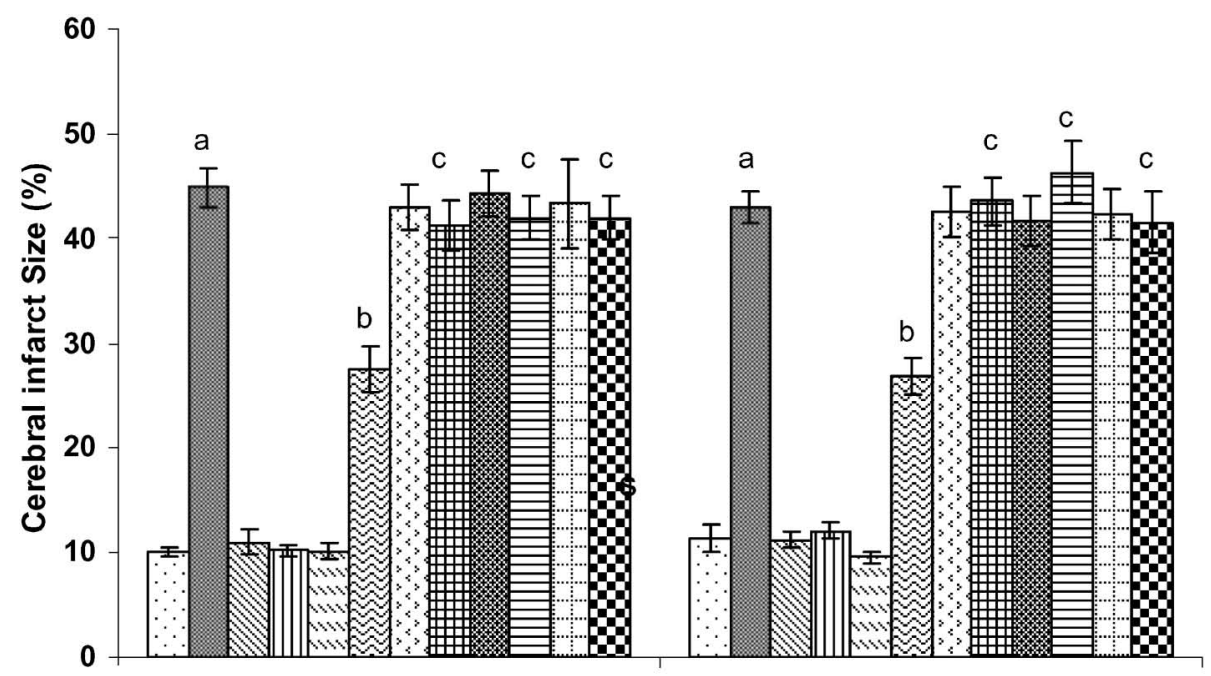

By volume

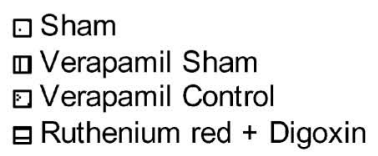

을 Control

$\mathrm{Q}$ Ruthenium red Sham $\boxplus$ Verapamil + Digoxin

$\square$ Dichlorobenzamil control

\section{By weight}

ه Digoxin Sham

\$ Digoxin PreCo

Ruthenium red Control

巴Dichlorobenzamil PoCo

Fig. 1. Effect of Pharmacological Preconditioning and Interventions on Ischemia Reperfusion Induced Cerebral Infarct Size Values are mean \pm S.E.M., $\mathrm{a}=p<0.001 v s$. Sham group, $\mathrm{b}=p<0.01 v s$. Control group, $\mathrm{c}=p<0.01 v s$. Digoxin preconditioning group. 


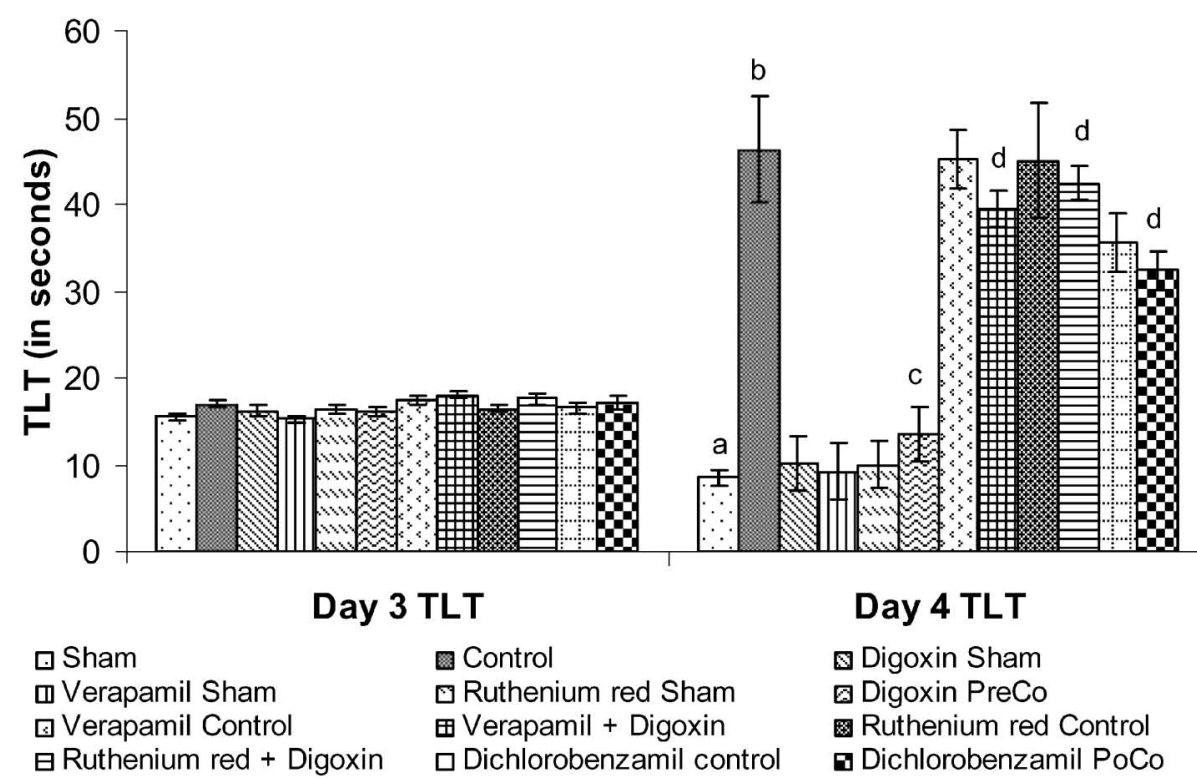

Fig. 2. Effect of Pharmacological Preconditioning and Interventions on Ischemia Reperfusion Induced Transfer Latency Time (TLT)

Values are mean \pm S.E.M., $\mathrm{a}=p<0.05 v$ s. day 3 TLT of Sham group, $\mathrm{b}=p<0.05$ vs. day 4 TLT of Sham group, $\mathrm{c}=p<0.05 v s$. day 4 TLT of Control group, $\mathrm{d}$ $=p<0.05 v$ s. day 4 TLT of Digoxin preconditioning group.

crease in day 4 TLT of control group thus indicating reversal of ischaemia and reperfusion induced impairment of memory. Further, pretreatment of verapamil, ruthenium red as well as 3,4-dichlorobenzamil control did not affect $\mathrm{I} / \mathrm{R}$ induced impairment of memory but significantly abolished digoxin preconditioning induced beneficial effects of memory (Fig. 2).

\section{Effect on Motor Performance}

Effect on fall down time using Rota-rod test

Global cerebral ischemia of $17 \mathrm{~min}$ followed by reperfusion for $24 \mathrm{~h}$ produced significant $(p<0.001)$ reduction in fall down time, as measured by rota-rod test, when compared to the sham groups. PP with digoxin, administered $24 \mathrm{~h}$ prior to ischemic insult significantly $(p<0.001)$ reversed I/ $\mathrm{R}$ induced reduction in fall down time. However, pretreatment of verapamil, ruthenium red as well as 3,4-dichlorobenzamil control did not affect $I / R$ induced reduction in fall down time but significantly $(p<0.01)$ abolished digoxin preconditioning induced effect on fall down time (Fig. 3).

Effect on motor incoordination score using inclined beam walking test Global cerebral ischemia of 17 min followed by reperfusion for $24 \mathrm{~h}$ produced significant rise $(p<0.001)$ in motor incoordination score, when compared to the sham groups as assessed by inclined beam walking test, after $12 \mathrm{~h}$ and $24 \mathrm{~h}$ of reperfusion. PP with digoxin, administered $24 \mathrm{~h}$ prior to ischemic insult attenuated $\mathrm{I} / \mathrm{R}$ induced increase in motor incoordination score in a significant manner $(p$ $<0.001)$. However, pretreatment of verapamil, ruthenium red as well as 3,4-dichlorobenzamil control did not affect $\mathrm{I} / \mathrm{R}$ induced motor incoordination but significantly $(p<0.001)$ abolished digoxin preconditioning induced effect on motor incoordination score in mice (Fig. 4).

\section{Effect on resistance to lateral push response}

Global cerebral ischaemia of $17 \mathrm{~min}$ followed by reperfusion for $24 \mathrm{~h}$ produced a significant $(p<$ $0.001)$ decrease in percentage of mice exhibiting resistance to lateral push in mice noted after $12 \mathrm{~h}$ and $24 \mathrm{~h}$ of reperfusion, when compared to the sham groups. PP with digoxin, administered $24 \mathrm{~h}$ prior to ischemic insult significantly $(p<0.001)$ attenuated I/ $\mathrm{R}$ induced decrease in percentage of mice demonstrating resistance to lateral push when compared to the control group. However, pretreatment of verapamil, ruthenium red as well as 3,4-dichlorobenzamil control did not affect $I / R$ induced decrease in percentage of mice exhibiting resistance to lateral push but significantly abolished $(p<0.001)$ digoxin preconditioning induced increase in the percentage of mice exhibiting resistance to lateral push (Fig. 5). 


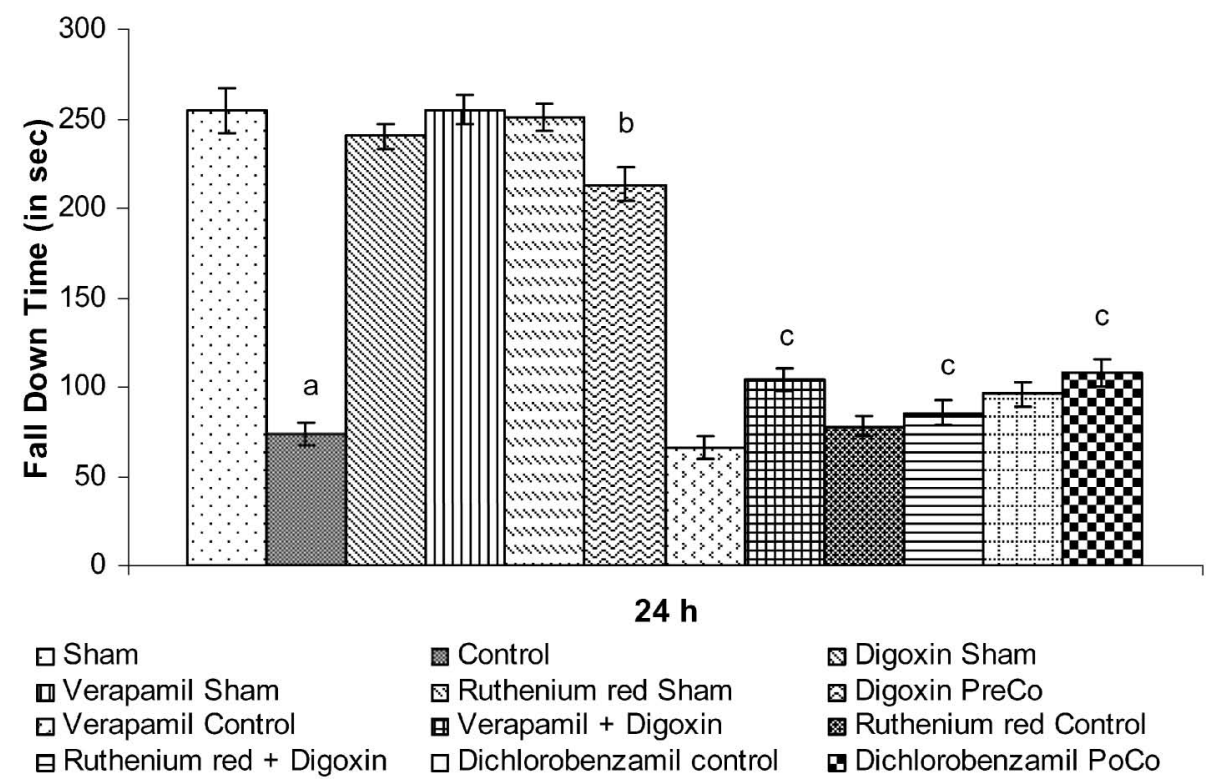

Fig. 3. Effect of Pharmacological Preconditioning and Interventions on Ischemia Reperfusion Induced Changes in Motor Performance (Fall Down Time) in Mice Using Rota Rod Test

Values are mean \pm S.E.M., $\mathrm{a}=p<0.001 v s$. Sham group, $\mathrm{b}=p<0.01 v s$. Control group, $\mathrm{c}=p<0.01 v s$. Digoxin preconditioning group.

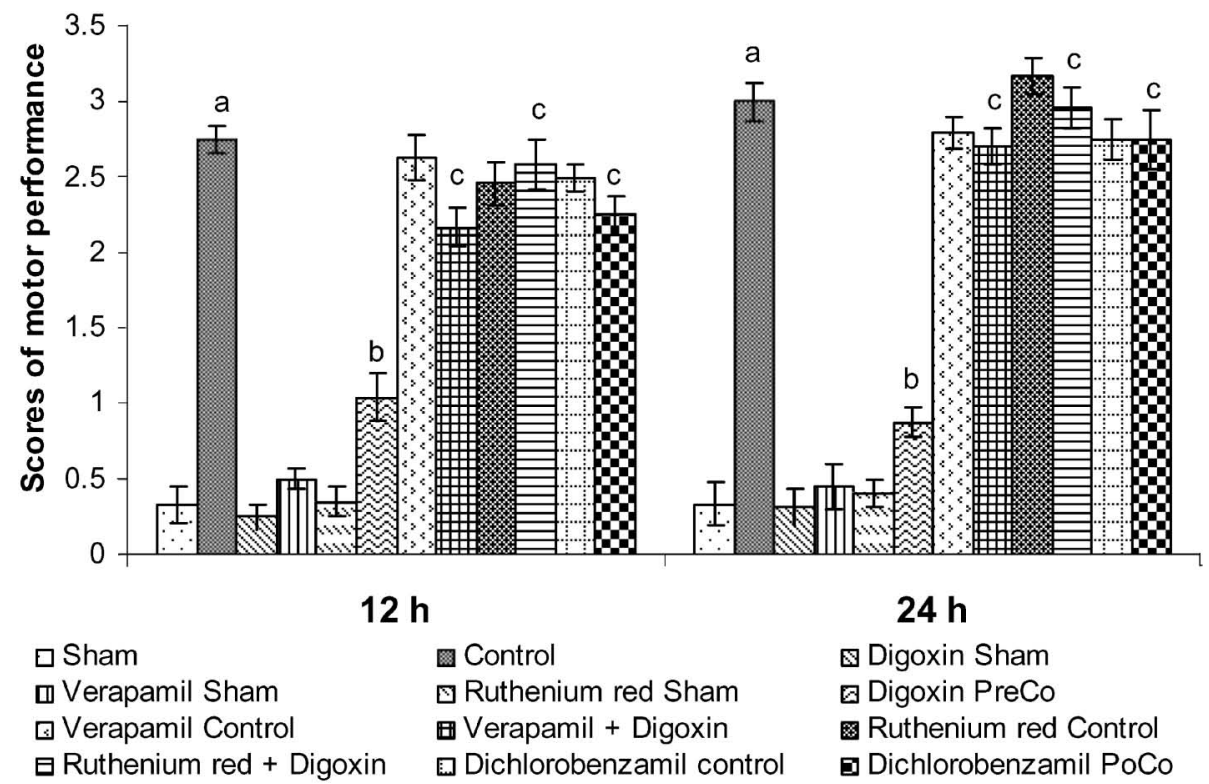

Fig. 4. Effect of Pharmacological Preconditioning and Interventions on Ischemia Reperfusion Induced Changes in Motor Performance (Score of Motor Performance) in Mice Using Inclined Beam Walk Test

Values are mean \pm S.E.M., $\mathrm{a}=p<0.001 v s$. Sham group, $\mathrm{b}=p<0.001 v s$. Control group, $\mathrm{c}=p<0.001 v s$. Digoxin preconditioning group.

\section{DISCUSSION}

The present study is carried out by employing male mice because it has been reported that high estrogen level itself exerts protection in cerebral ischemia reperfusion injury. ${ }^{31)}$ Global cerebral ischemia and reperfusion model employed in the present study is reported to simulate the clinical situation of cerebral ischemia. ${ }^{32,33)}$ Cerebral ischemia has been reported to impair memory because hippocampal neurons are susceptible to the deleterious effects of ischaemia and reperfusion and hippocampus is involved in regulation of memory. ${ }^{34)}$ Cerebral ischemia is further documented to impair motor ability as well. ${ }^{35)}$ There- 


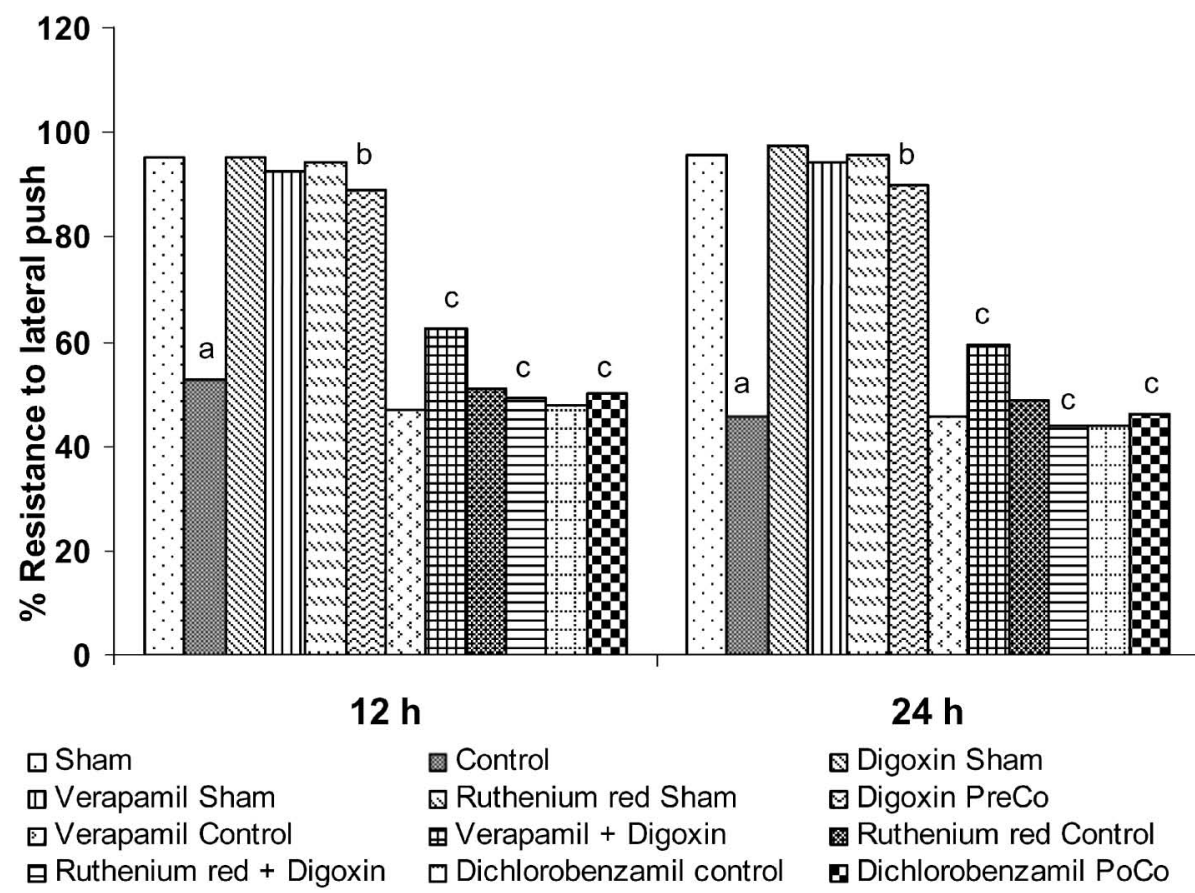

Fig. 5. Effect of Pharmacological Preconditioning and Interventions on Ischemia Reperfusion Induced Changes in Motor Performance in Mice Using Lateral Push Test

Values are mean \pm S.E.M., $\mathrm{a}=p<0.001 v s$. Sham group, $\mathrm{b}=p<0.001 v s$. Control group, $\mathrm{c}=p<0.01 v s$. Digoxin preconditioning group.

fore, in the present investigation we employed elevated plus maze test to assess memory and rota-rod test, inclined beam walk test and lateral push test for evaluation of motor coordination. In our study, global cerebral ischemia and reperfusion produced a significant rise in infarct size and induced impairment of memory as well as motor coordination. These findings are in line with our earlier reports ${ }^{9-12)}$ and reports from other laboratories. ${ }^{23,25)}$

Recently it was reported that a significant impairment of memory and motor coordination can be induced by increasing the extent of ischemic insult to 17 min. ${ }^{36)}$ Therefore, we adopted the procedure described by Wong et al, who reported that global ischemic insult of 17 minutes duration produce ischemic damage along with excellent behavioral impairments in mice. ${ }^{36)}$

In the present investigation digoxin, a cardiac glycoside and a potent inhibitor of $\mathrm{Na}^{+} \mathrm{K}^{+}$ATPase throughout the body including the brain tissue, ${ }^{20-22)}$ has been shown to exert a significant PP like neuroprotective effect as manifested in terms of decrease in cerebral infarct size, improvement of memory and motor incoordination. The results of present study support the previous report, whereby a $\mathrm{Na}^{+} \mathrm{K}^{+}$ATPase inhibitor has been shown to trigger precondition- ing like effects in rat myocardium. ${ }^{19)}$ However, ours is the first report implicating the neuroprotective action of digoxin induced pharmacological preconditiong and it is most likely that modulation of $\mathrm{Na}^{+} \mathrm{K}^{+}$ATPase is responsible for the noted actions of digoxin.

$\mathrm{Na}^{+} \mathrm{K}^{+}$ATPase is a ubiquitous transmembrane enzyme that transports $\mathrm{Na}^{+}$and $\mathrm{K}^{+}$across the plasma membrane by hydrolysis of ATP. Inhibition of $\mathrm{Na}^{+}$ $\mathrm{K}^{+}$ATPase results in increased intracellular calcium concentration via sodium calcium exchanger. ${ }^{20,21)}$ Calcium induced calcium release is a general mechanism that most cells use to amplify $\mathrm{Ca}^{+2}$ signals. ${ }^{37)}$ Both L-type calcium channels and intracellular ryanodine receptors have been shown to control the intracellular kinetics of calcium ions. In cardiac cells, this mechanism is operated between voltage gated Ltype calcium channels in the plasma membrane and calcium release channels (Ryanodine receptors) in sarcoplasmic reticulum. ${ }^{38,39)}$ Similarly major pathway for calcium entry into neurons is via voltage gated calcium channels present on membrane surface of neurons $\mathrm{s}^{40)}$ and Ryanodine receptors present in sarcoplasmic reticulum.

The calcium ions are well reported to play an important role in regulation of synaptic transmission and are essential for intracellular functions such as 
neurotransmitter release, enzyme activity, membrane excitability and, gene expression. ${ }^{41,42)}$ Further it has been well documented that $\mathrm{iCa}^{+2}$ plays a key role in the multiple aspects of various forms of protective phenomenon like ischemic preconditioning and pharmacological preconditioning. ${ }^{17,18)}$ Therefore, the noted neuroprotective effect of digoxin induced pharmacological preconditioning in our study is speculated to involve calcium dependent mechanisms. This contention is further supported by our study with verapamil (L-type calcium channel blocker in brain), ${ }^{43,44)}$ calcium release inhibitor ruthenium red (Ryanodine receptors blocker in brain) ${ }^{45)}$ and 3, 4-dichlorobenzamil $\left(\mathrm{Na}^{+} / \mathrm{Ca}^{2+}\right.$ exchanger inhibitor), ${ }^{46)}$ all of which abolished neuroprotective effects of digoxin induced pharmacological preconditioning. Hence, it may be put forth that, digoxin exhibits pharmacological preconditioning of brain in mice and that intracellular calcium homeostasis plays a fundamental role in this digoxin preconditioning induced neuroprotection which may be further mediated by an increase in the intracellular calcium levels via L-type calcium channels, Ryanodine receptors and $\mathrm{Na}^{+} / \mathrm{Ca}^{2+}$ exchanger. Further, digoxin has been well known to have a generalized influence on the blood flow dynamics throughout the body via its cardiotonic activity. However, role of such an effect of digoxin in mediating the preconditioning induced protection has been transiently avoided in the present study by employing proper control groups. This fact, in principle, does not negate the possibility of the involvement of digoxin induced hemodynamic effects in causing the preconditioning and merits future investigation into its possible role in the observed protection.

\section{CONCLUSION}

Therefore, it is concluded that the digoxin exhibits pharmacological preconditioning of brain in mice and digoxin preconditioning induced neuroprotection is possibly mediated by an increase in the intracellular calcium levels via L-type calcium channels, Ryanodine receptors and $\mathrm{Na}^{+} / \mathrm{Ca}^{2+}$ exchanger.

Acknowledgements The authors are grateful to Dr. Ashok Kumar Tiwary, Head, Department of Pharmaceutical Sciences and Drug Research, Punjabi University, Patiala, India, Dr. Madhu Chitkara, Director, Chitkara Institute of Engineering and Technology, Distt. Patiala-140 401, India, Dr. Ashok
Chitkara, Chairman, Chitkara Educational Trust, Chandigarh, India and Dr. Manoj Kumar, Principal, Chitkara College of Pharmacy, Distt. Patiala-140 401, India, for supporting the study.

\section{REFERENCES}

1) Murray C.-E., Jennings R.-B., Reimer K. A., Circulation, 74, 1124-1136 (1986).

2) Kitagawa K., Matsumoto M., Tagaya M., Hata R., Ueda H., Niinobe M., Handa N., Fukunaga R., Kimura K., Mikoshiba K., Brain Res., 528, 21-24 (1990) .

3) Lee H.-T., Emala C.-W., Am. J. Physiol. Renal Physiol., 278, F380-F387 (2000).

4) Ferencz A., Racz B., Gasz B., Benko L., Jancso G., Kurthy M., Roth E., Microsurgery, 26 (1) , 54-57 (2006) .

5) Mounsey R.-A., Pang C.-Y., Boyd J.-B., Forrest C., J. Otolaryngol., 21(5), 315-320 (1992).

6) Fung J.-J., Liver Transpl., 7(4), 300-301 (2001).

7) Matsuyama K., Chiba Y., Ihaya A., Kimura T., Tanigawa N., Muraoka R., Ann. Thorac. Surg., 63, 1315-1320 (1997).

8) McCormick P.-H., Chen G., Tlerney S., Kelly C.-J., Bouchier-Hayes D.-J., J. Surg. Res., 109 (1), 24-30 (2003).

9) Rehni A.-K., Shri R., Singh M., Indian J. Exp. Biol., 45, 247-252 (2007).

10) Rehni A.-K., Singh N., Pharmacol. Rep., 59, 197-203 (2007).

11) Rehni A.-K., Singh N., Singh A.-S., Yakugaku Zasshi, 127, 1013-1020 (2007).

12) Rehni A.-K., Bhateja P., Singh N., Jaggi A.S., Fundamental Clin. Pharmacol., 22, 179188 (2008).

13) Riess M.-L., Stowe1 D.-F., Warltier D.-C., Am. J. Physiol. Heart Circ. Physiol., 286, H1603-H1607 (2004) .

14) Yellon D.-M., Dana A., Circ. Res., 87, 543550 (2000).

15) Schulz R., Post H., Vahlhaus C., Heusch G., Circulation, 98, 1022-1029 (1998).

16) Schulz R., Gres P., Heusch G., Am. J. Physiol. Heart Circ. Physiol., 280, H2175-H2181 (2001).

17) Miyawaki H., Ashraf M., Circ. Res., 80, 790799 (1997). 
18) Miyawaki H., Zhou X., Ashraf M., Circ. Res., 79, 137-146 (1996).

19) Pierre S.-V., Yang C., Yuan Z., Seminerio J., Mouas C., Garlid K.-D., Dos-Santos P., Xie Z., Cardiovasc. Res., 73, 488-496 (2007).

20) Hauptman P.-J., Kelly R.-A., Circulation, 99, 1265-1270 (1999).

21) Akera T., Brody T.-M., Pharmacol. Rev., 29, 187-220 (1977).

22) Krstić D., Tomić N., Krinulović K., Vasić V., J. Enzyme Inhib. Med. Chem., 21 (4), 471475 (2006).

23) Himori N., Wantanabe H., Akaike N., Kurasawa M., ltoh J., Tanaka Y., J., Pharmacol. Meth., 23, 311-327 (1990).

24) Bochelen D., Rudin M., Sauter A., J. Pharmacol. Exp. Ther., 288, 653-659 (1999).

25) Gupta R., Singh M., Sharma A., Pharmacol. Res., 48(2), 209-215 (2003).

26) Itoh J., Nabeshima T., Kameyama T., Psychopharmacology, 101, 27-32 (1990).

27) Zdenek H., Ivan K., Behav. Brain Res., 91, 83-89 (1998).

28) Dunham N.-W., Miya T.-S., J. Am. Pharm. Assoc. (Baltim)., 46 (3) , 208-209 (1957).

29) Feeney D.-M., Boyeson M.-G., Linn R.-T., Murray H.-M., Dail W.-G., Brain Res., 211, 67-77 (1981).

30) Bederson J.-B., Pitts L.-H., Tsuji M., Nishimur M.-C., Davis R.-L., Bartowski H., Stroke, 17, 472-476 (1986).

31) Zhai P., Eurell T.-E., Cotthaus R., Jeffery E.-H., Bahr J.-M., Gross D.-R., Am. J. Physiol. Heart Circ. Physiol., 279, H2766-H2775 (2000)

32) Alonsode de Lecinana M., Diez-Tejedor E., Cearcellar F., Roda J.-M., Cerebrovasc. Dis.,
11 (1), 20-30 (2001).

33) Neumar R.-W., Annals. of Emergency Medicine, 36, 483-506 (2000).

34) Jenkins L.-W., Povlishock J.-T., Lewelt W., Miller J.-D., Becker D.-P., Acta Neuropathol., 5, 205-220 (1981).

35) Dobkin B.-H., Clin. Geriat. Med., 7, 507-523 (1991).

36) Wong A.-M., Hodges H., Horsburgh K., Brain Res., 1063, 140-150 (2005).

37) Wang S.-Q., Song L.-S., Lakatta E.-G., Cheng H., Nature, 410, 592-596 (2001).

38) Fabiato A., J. Gen. Physiol., 85, 247-289 (1985)

39) Mcgarry S.-J., Williams A.-J., Br. J. Pharmacol., 108, 1043-1050 (1993).

40) Budde T., Munsch T., Pape H.-C., Eur. J. Neurosci., 10(2), 586-597 (1998).

41) Finkbeiner S., Greenberg M.-E., J. Neurobiol., 37, 171-189 (1998).

42) Carafoli E., Santalla L., Branca D., Brini M., Crit. Rev. Biochem. Mol. Biol., 36, 107-260 (2001).

43) Bishnoi M., Chopra K., Kulkarni S.-K., Neurochem. Res., 33(9), 1869-1880 (2008).

44) Lashgari R., Motamedi F., Noorbakhsh S.-M., Zahedi-Asl S., Komaki A., Shahidi S., Haghparast A., Neurosci. Lett., 415 (2) , 174178 (2007).

45) Ma Y.-Y., Huo H.-R., Li C.-H., Zhao B.-S., Li L.-F., Sui F., Guo S.-Y., Jiang T.-L., Biol. Pharm. Bull., 31, 426-430 (2008).

46) Márián T., Szabó-Péli J., Németh E., Trón L., Friedlander E., Szabó A., Balkay L., Veress G., Krasznai Z., Eur. J. Pharm. Sci., 30 (1) , 56-63 (2007). 